\title{
EFFECT OF APROTININ ON VASCULAR REACTIVITY OF CORONARY BYPASS GRAFTS
}

Sean Allen, $\mathrm{PhD}$

Nikos Anastasiou, MD

David Royston, MD

Rodolfo Paniagua, MD

Magdi Yacoub, MD
Objective: Aprotinin reduces postoperative bleeding and the need for transfusion after cardiopulmonary bypass. The current clinical concern about aprotinin is that it may increase the incidence of postoperative graft thrombosis and thromboembolic phenomena. The fact that the mechanism of action of aprotinin is still not completely elucidated and that its effects on the vascular reactivity of bypass conduits are unknown raise doubts regarding its safety. In an attempt to clarify these issues we investigated the vascular reactivity of the human saphenous vein and internal thoracic artery to a range of vasoconstrictor agents in the presence or absence of aprotinin. Methods: Human saphenous vein was obtained from 24 patients and internal thoracic artery from 7 patients undergoing coronary artery bypass. Vessels were set up in organ baths to record changes in vessel wall tension. Results: Endothelium-dependent relaxations to acetylcholine in saphenous vein rings were unaffected after aprotinin treatment. Contractions to the thromboxane analog $\mathrm{U} 46619$ were significantly attenuated after aprotinin treatment in the saphenous vein. Maximum responses were reduced from control values of $88 \pm 7.5 \mathrm{mN}$ to $49.3 \pm 4.8 \mathrm{mN}$ with $1 \mu \mathrm{mol} / \mathrm{L}$ doses of aprotinin $(p<0.05)$ and $36.6 \pm 4.8 \mathrm{mN}$ with $10 \mu \mathrm{mol} / \mathrm{L}$ doses of aprotinin $(p<0.05)$. There was no attenuation of contractions induced by 5-hyroxytryptamine or noradrenaline after aprotinin incubations. Furthermore, contractions to $\mathrm{U} \mathbf{4 6 6 1 9}$ in the internal thoracic artery were unaffected by aprotinin. Conclusion: Our data show that there is a preservation of endothelium-dependent responses to acetylcholine and a reduced U46619 vasoconstrictor action on the saphenous vein after aprotinin treatment. Thus the direct effect of aprotinin on the vessel wall could counteract the potential effect of its prothrombotic action on graft patency. (J Thorac Cardiovasc Surg 1997;113:319-26)
$\mathrm{T}$ he nonspecific serine protease inhibitor aprotinin reduces postoperative bleeding and the need for transfusion after cardiopulmonary bypass. ${ }^{1-3}$ The mechanism of action of aprotinin is still unknown. It is, however, recognized that aprotinin can act to inhibit plasmin ${ }^{2}$ and other factors in the coagulation cascade. In addition, there is evidence to suggest that aprotinin can inhibit certain control proteases

From the Department of Cardiothoracic Surgery, Harefield Hospital, Harefield, Middlesex, United Kingdom.

Received for publication Feb. 23, 1996; revisions requested April 8, 1996; revisions received July 30, 1996; accepted for publication August 23, 1996.

Address for reprints: Magdi Yacoub, MD, Department of Cardiothoracic Surgery, Harefield Hospital, Harefield, Middlesex, UB9 6JH, United Kingdom.

Copyright (C) 1997 by Mosby-Year Book, Inc.

$0022-5223 / 97 \$ 5.00+0 \quad \mathbf{1 2 / 1 / 7 7 5 7 0}$ in coagulation and fibrinolysis, in particular, activated protein $\mathrm{C}$ and tissue plasminogen activator. ${ }^{4}$ Aprotinin may also improve hemostasis by preserving the components of platelet adhesion, ${ }^{5,6}$ which are otherwise damaged during the initial phase of cardiopulmonary bypass. ${ }^{7}$ Platelet adhesion and activation during bypass can result in production of a variety of mediators including 5-hydroxytryptamine (5-HT) and thromboxane $\mathrm{A}_{2}\left(\mathrm{TXA}_{2}\right)$, which are known to affect endothelial and smooth muscle cell function. Because the regulated release of platelet stimulators and inhibitors by endothelial cells is essential to the control of platelet adhesion and activation, ${ }^{8}$ it is possible that aprotinin could directly influence vascular reactivity and graft performance by enhancing platelet stimulation or by the interaction of platelets with the vessel wall, or both. Furthermore, the response of smooth muscle cells to vasoactive mediators released from activated plate- 


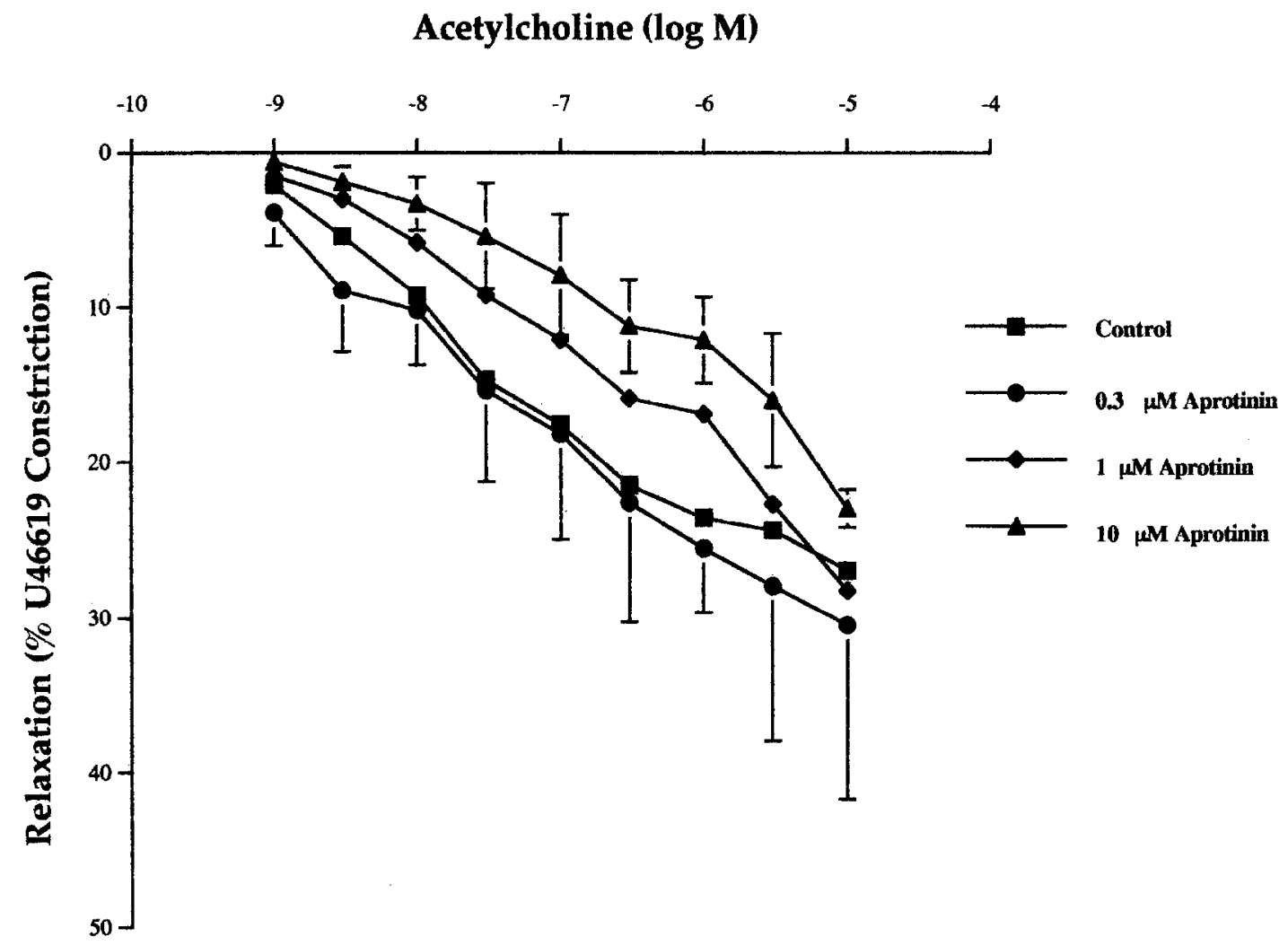

Fig. 1. Effect of aprotinin concentration on endothelium-dependent relaxations to acetylcholine in the human saphenous vein $(1 \mathrm{nmol} / \mathrm{L}$ to $10 \mu \mathrm{mol} / \mathrm{L} ; n=6)$.

lets could also be a target for the actions of aprotinin.

Although the practical use of aprotinin for patients undergoing cardiopulmonary bypass has been widely endorsed because of its hemostasis-preserving effect, clinical reports have questioned the overall safety of aprotinin therapy. 9,10 The current concern about aprotinin is that it may have an overall prothrombotic effect, thus increasing the incidence of postoperative graft thrombosis and thromboembolic phenomena. Although controlled clinical studies have failed to show or confirm these problems the fact that the mechanism of action of aprotinin is still not completely elucidated and that its effects on the vascular reactivity of bypass conduits unknown raise doubts regarding its safety. In an attempt to clarify these issues we investigated the reactivity of the human saphenous vein and internal thoracic artery (ITA) to the endothelium-dependent vasodilator acetylcholine and to a range of vasoconstrictor agents released from platelets or administered perioperatively in the presence or absence of aprotinin.

\section{Material and methods}

Tissue preparation. Specimens of human undistended saphenous vein from 24 patients and ITA from 7 patients were obtained as excess to requirements during coronary artery bypass operations. Informed consent was obtained from each patient and the study was approved by the Harefield Hospital ethical committee. No patient incorporated in the study was receiving aprotinin perioperatively. Vessels were immediately placed in modified Tyrode's solution of the following composition (in millimoles per liter): $\mathrm{NaCl} 136.9 ; \mathrm{NaHCO}_{3} 11.9 ; \mathrm{KCl} 2.7 ; \mathrm{NaH}_{2} \mathrm{PO}_{4}$ $0.4 ; \mathrm{MgCl} 2.5 ; \mathrm{CaCl}_{2} 2.5$; glucose 11.1; and disodium ethylenediaminetetraacetic acid 0.04 . The blood vessels were then dissected free from connective tissue under a light microscope. Rings of saphenous vein and ITA were then mounted for isometric tension recording in organ baths filled with modified Tyrode's solution aerated with a $95 \%$ oxygen and $5 \%$ carbon dioxide mixture. The temperature of the organ baths was maintained at $37^{\circ} \mathrm{C}$.

Experimental protocol. Before each experiment, saphenous vein ring segments were stretched to an initial tension of $6 \mathrm{gm}$ and the ITAs were stretched to $4 \mathrm{gm}$. These preloads have been shown to be optimal for the maximal isometric contraction in response to a $90 \mathrm{mmol} / \mathrm{L}$ dose of potassium chloride. The segments were allowed to relax for a period of 60 minutes. When resting tension was stable each ring was challenged with a $90 \mathrm{mmol} / \mathrm{L}$ dose of 


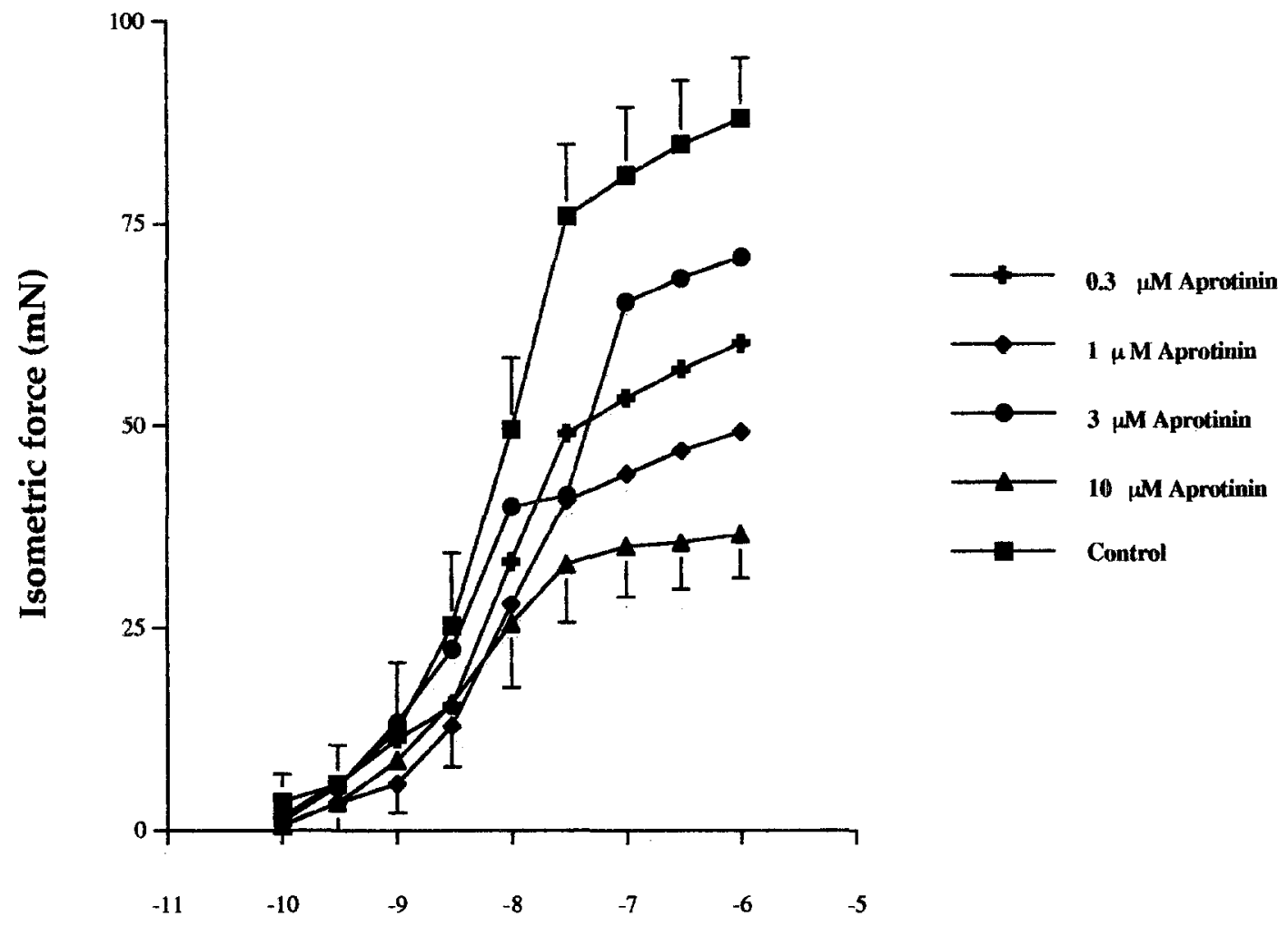

U46619 ( $\log M)$

Fig. 2. Effect of aprotinin concentration on smooth muscle vasoconstriction to U46619 in the human saphenous vein $(0.1 \mathrm{nmol} / \mathrm{L}$ to $1 \mu \mathrm{mol} / \mathrm{L})$. Contractions to $\mathrm{U} 46619$ were significantly attenuated $(p<0.05$; $n=6)$ at both $1 \mu \mathrm{mol} / \mathrm{L}$ and $10 \mu \mathrm{mol} / \mathrm{L}$ doses of aprotinin.

Table I. Effect of aprotinin concentration on potency of acetylcholine, U46619, 5-HT, and noradrenaline in the human saphenous vein and of U46619 in the ITA

$\mathrm{pD}_{2}$ values by aprotinin dose

\begin{tabular}{lccccc} 
& $3 \times 10^{-7} \mathrm{~mol} / \mathrm{L}$ & $10^{-6} \mathrm{~mol} / \mathrm{L}$ & $3 \times 10^{-6} \mathrm{~mol} / \mathrm{L}$ & $10^{-5} \mathrm{~mol} / \mathrm{L}$ & $\mathrm{Conirol}$ \\
\hline U46619 (SV) & $8.3 \pm 0.3$ & $8.1 \pm 0.2$ & $8.2 \pm 0.3$ & $8.2 \pm 0.2$ & $8.3 \pm 0.3$ \\
NAD (SV) & $7.4 \pm 0.2$ & $7.2 \pm 0.2$ & $7.1 \pm 0.1$ & $7.2 \pm 0.1$ & $7.0 \pm 0.1$ \\
5-HT (SV) & $7.2 \pm 0.2$ & $7.1 \pm 0.2$ & $7.0 \pm 0.1$ & $7.3 \pm 0.3$ & $7.0 \pm 0.2$ \\
Ach (SV) & $7.8 \pm 0.2$ & $6.4 \pm 0.4$ & $\mathrm{NC}$ & $7.2 \pm 0.5$ & $7.1 \pm 0.2$ \\
U46619 (ITA) & $\mathrm{NC}$ & $8.6 \pm 0.2$ & $\mathrm{NC}$ & $8.8 \pm 0.1$ & $8.3 \pm 0.4$ \\
\hline
\end{tabular}

$S V$, Saphenous vein; $N A D$, noradrenaline; $A c h$, acetylcholine; $N C$, not calculated.

potassium chloride (the bath solution was changed between doses when the responses reached a plateau) to verify the reactivity of the vessel. Vessels in which the $\mathrm{KCl}$ response was less than $10 \mathrm{mN}$ were discarded to reduce the inherent differences in reactivity observed between patients. After two potassium chloride responses were obtained, the vessel segments were washed and allowed to reequilibrate for 30 minutes. After this period ring segments were incubated for 1 hour with a range of aprotinin concentrations that are normally used clinically under our high-dose regimen $(0.3 \mu \mathrm{mol} / \mathrm{L}$ to $10 \mu \mathrm{mol} / \mathrm{L}){ }^{11}$ At the end of the incubation period the rings were assessed with respect to their ability to vasodilate or vasoconstrict in response to a range of vasoactive mediators still in the presence of aprotinin. Only one drug was assessed in each vessel segment.

Endothelial function. To assess the effect of aprotinin on endothelial function in the saphenous vein, ring seg- 


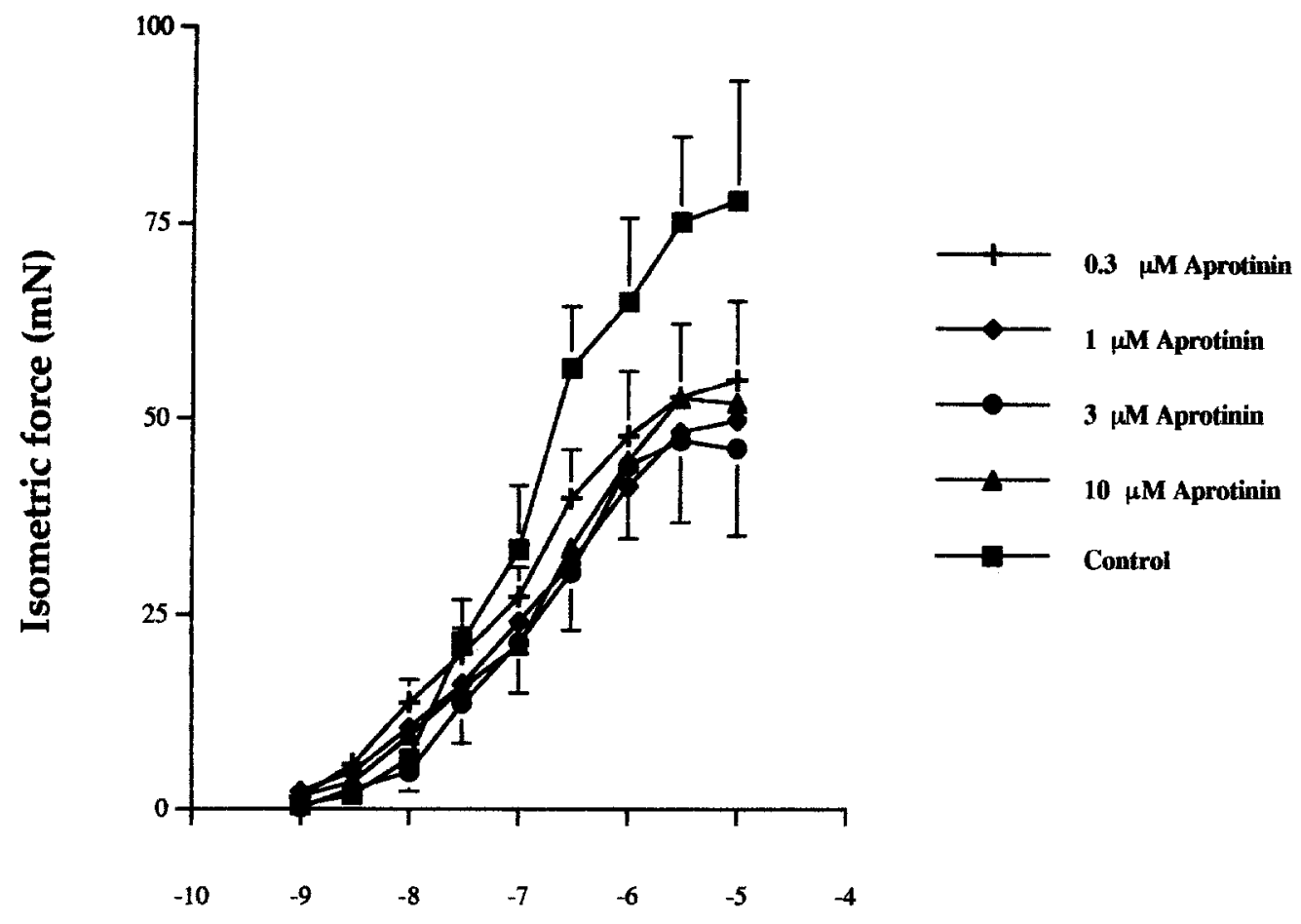

Noradrenaline $(\log \mathrm{M})$

Fig. 3. Effect of aprotinin concentration on smooth muscle vasoconstriction to noradrenaline in the human saphenous vein $(1 \mathrm{nmol} / \mathrm{L}$ to $10 \mu \mathrm{mol} / \mathrm{L} ; n=6)$.

ments were preconstricted with the $\mathrm{TXA}_{2}$ analog U46619 $(1 \mathrm{nmol} / \mathrm{L})$ by adding the drug to the Tyrode's solution bath. Once a stable plateau was reached, cumulative additions of the endothelium-dependent vasodilator acetylcholine $(1 \mathrm{nmol} / \mathrm{L}$ to $1 \mu \mathrm{mol} / \mathrm{L})$ were made in the presence and absence of aprotinin.

Smooth muscle cell function. To assess the effect of aprotinin on vascular smooth muscle cell function, vessel segments were challenged with either 5-HT, U46619, or noradrenaline by addition of increasing concentrations of each agonist to the baths in a cumulative manner.

Analysis of data. The relaxations were expressed as percentage decrease in tension of the contraction induced by U46619. Contractions were measured as absolute tension in grams. For analysis of the responses the concentration of agonist exhibiting 50\% of the maximum response (EC50) was calculated. EC50 values for each concentration-response curve were obtained by a probit transformation of the data points to linearize the sigmoidal curves. Linear-regression analysis of data points versus log concentration above and below the $50 \%$ response level was then obtained. The values were transformed into geometric means ( $p \mathrm{D}_{2}$ values), which were approximately normally distributed following analysis of frequency of values over a range of standard deviation units from the mean. The efficacy of the saphenous vein and ITA to all agonists was represented by the maximum contractile response. All results are shown as means plus or minus the standard error of the mean where $n$ equals the number of patients from whom the vessels were obtained. Statistical analysis was done by a repeated-measures analysis of variance followed by paired $t$ tests with Bonferroni's correction for multiple comparisons (Primer Biostatistics, Stanton A. Glantz) on each ring segment to address dependencies between observations in the same tissue and tissues from the same person. In each case the same number of tissue rings per agonist was used from each patient to look at differences between treatments at different doses of constrictor. Two-sided values of $p<0.05$ were considered to be statistically significant.

\section{Results}

Effect of aprotinin on endothelial function. Endothelium-dependent relaxations to acetylcholine in saphenous vein ring segments after incubation with aprotinin were unaffected in relation to control responses (Fig. $1 ; n=6$ ). There was no significant difference in U46619 constrictions used for providing a pretension for acetylcholine relaxations be- 


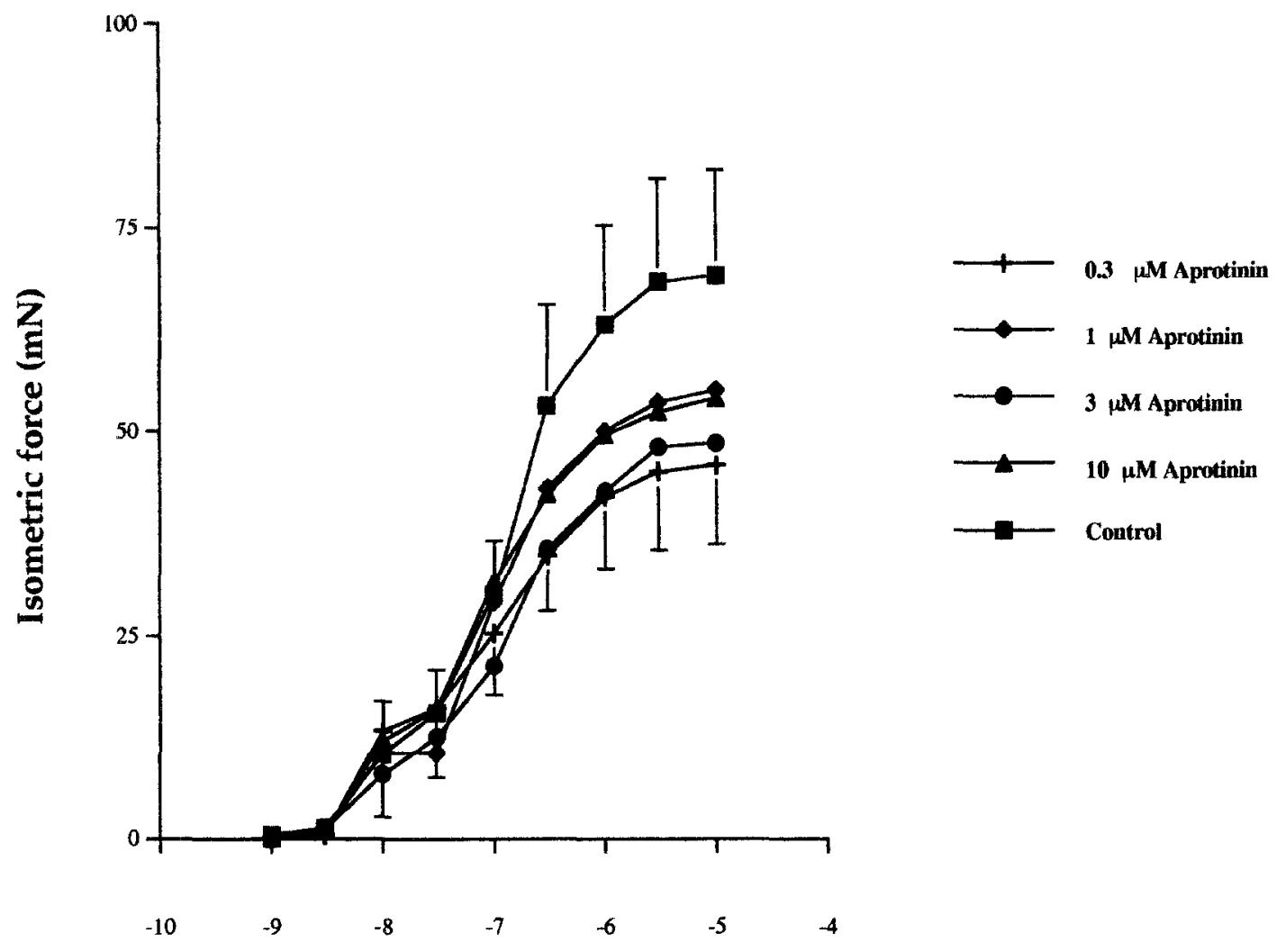

\section{5-HT $(\log$ M)}

Fig. 4. Effect of aprotinin concentration on smooth muscle vasoconstriction to 5-HT in the human saphenous vein $(1 \mathrm{nmol} / \mathrm{L}$ to $10 \mu \mathrm{mol} / \mathrm{L} ; n=6)$.

tween control and aprotinin-treated segments. Also, comparison of the sensitivity $\left(p \mathrm{D}_{2}\right)$ of acetylcholine between control and aprotinin groups showed a maximum log shift of approximately onefold (7.1 vs 7.8 and 7.1 vs 6.4 , respectively), which was statistically nonsignificant (Table I).

Effect of aprotinin on vascular smooth muscle cell function. Additions of the $\mathrm{TXA}_{2}$ analog U46619, noradrenaline, and 5-HT all produced concentration-dependent contractions of saphenous vein segments. In all cases the responses of the tissues to each agonist were similar for each patient with no evidence of large variations in reactivity, which could bias the results. Furthermore, when the results were expressed as a percentage of the response to $\mathrm{KCl}$ (to normalize for differences in tissue reactivity) there was no difference in the responses to each constrictor (data not shown). Therefore all the tissue rings from the different patients were averaged among all the various treatments. The responses to U46619 were attenuated after incubations with aprotinin (Fig. 2; $n=$ 6 ). The maximum responses were reduced from a control value of $88 \pm 7.5 \mathrm{mN}$ to $49.3 \pm 4.8 \mathrm{mN}$ with a $1 \mu \mathrm{mol} / \mathrm{L}$ dose of aprotinin $(p<0.05, n=$ 6) and to $36.6 \pm 5.4 \mathrm{mN}$ with a $10 \mu \mathrm{mol} / \mathrm{L}$ dose of aprotinin $(p<0.05, n=6)$. The contractile responses to noradrenaline in the presence of aprotinin were also depressed, although this did not reach statistical significance (Fig. $3 ; p=0.3$, $n=6$ ). Similarly, contractions induced by $5-\mathrm{HT}$ were attenuated in the presence of aprotinin but this was also not significant (Fig. $4 ; p=0.3, n=$ 6).

In contrast to findings in the saphenous vein, contractions to U46619 were unaffected by aprotinin treatment in the ITA (control value $37.8 \pm 5.1 \mathrm{mN}$ versus $37.2 \pm 6.0 \mathrm{mN}$ with a $1 \mu \mathrm{mol} / \mathrm{L}$ dose of 


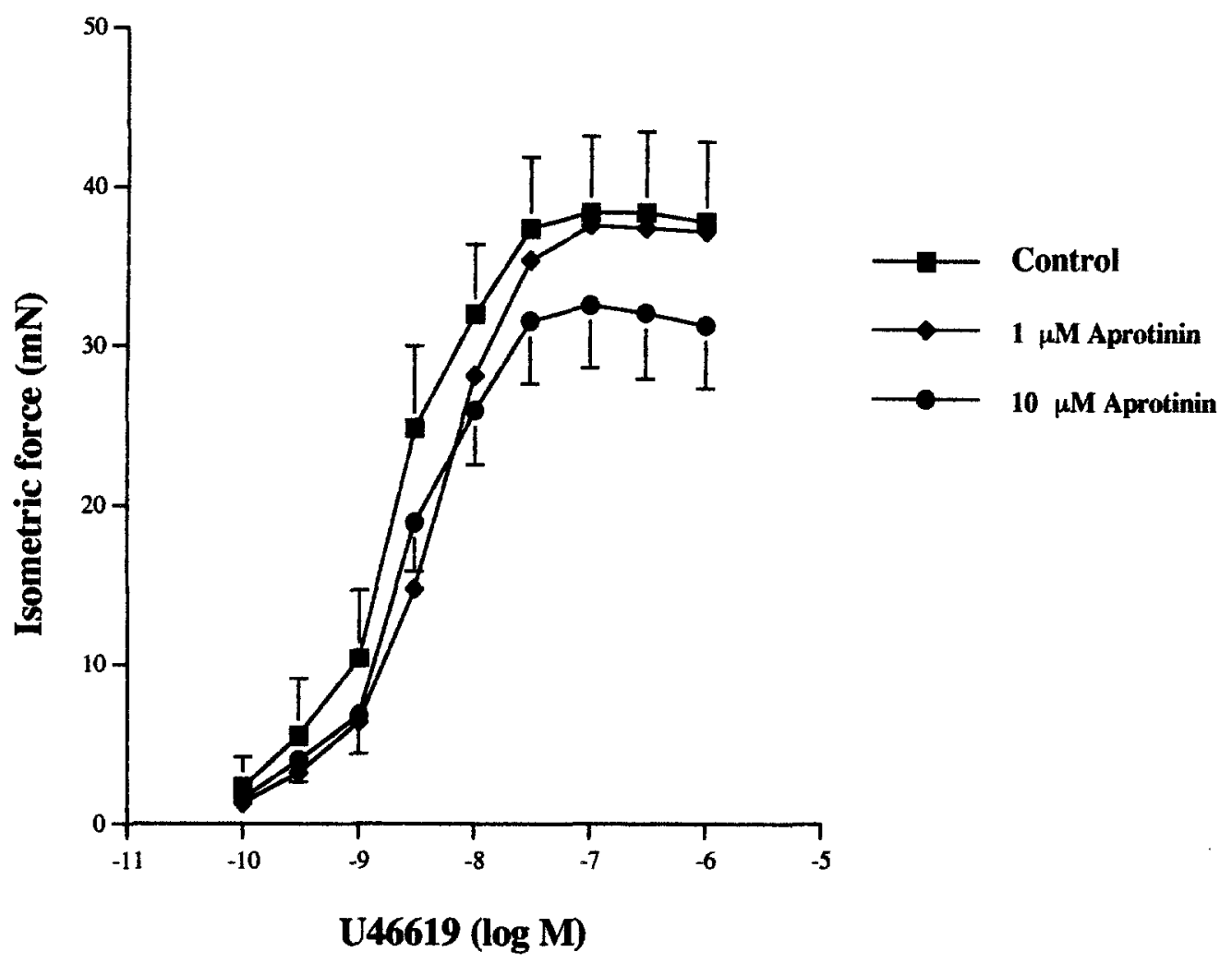

Fig. 5. Effect of aprotinin concentration on smooth muscle vasoconstriction to U46619 in the human ITA $(0.1 \mathrm{nmol} / \mathrm{L}$ to $1 \mu \mathrm{mol} / \mathrm{L} ; n=6)$.

aprotinin $[p=0.2, n=7]$ and versus $31.3 \pm 3.9 \mathrm{mN}$ with a $10 \mu \mathrm{mol} / \mathrm{L}$ dose of aprotinin $[p=0.2, n=7]$ ) (Fig. 5). In addition, there was no significant difference in $p \mathrm{D}_{2}$ values between control and aprotinintreated vessels in response to U46619, noradrenaline, or 5-HT in either the vein or artery (Table I).

\section{Discussion}

This study showed that exposure of human coronary bypass grafts to aprotinin, in a clinically relevant dose range, attenuated the U46619-induced smooth muscle cell vasoconstriction in the saphenous vein but not in the ITA. Furthermore, aprotinin did not affect endothelium-dependent relaxations to acetylcholine in the saphenous vein.

High-dose aprotinin is being used with increasing frequency to reduce perioperative blood loss during cardiac operations with the use of cardiopulmonary bypass. Aprotinin is a basic polypeptide that inhibits serine proteases: it inhibits a wide range of serine proteases from plasmin to kallikrein to trypsin and chymotrypsin. ${ }^{12}$ Excessive kallikrein is formed from its precursor prekallikrein during cardiopulmonary bypass, during activation of factor XII by the artificial surface of the bypass equipment, and by the exposed subendothelial tissues of the surgically cut vessels. ${ }^{13}$ Together with the antiplasmin effect of aprotinin, inhibition of kallikrein has a powerful antifibrinolytic effect by indirectly limiting the formation of activators of plasminogen. ${ }^{4}$ Aprotinin is also known to have a preservative effect on platelet function that seems to be important in its ability to reduce blood loss. $5,6,14$

Vascular endothelium plays an important part in the control of the coagulation pathway and the limitation and localization of the clotting process. An important substance released from the endothelium that is involved in the modulation of hemostasis and thrombosis is endothelium-derived nitric oxide. Nitric oxide can inhibit the adherence of platelets to endothelial cells. ${ }^{15,16}$ A reduction in the release of nitric oxide would increase adherence of platelets to endothelial cells, favoring the formation of a platelet plug and therefore arresting bleeding. 
The present data show no evidence of a reduction in acetylcholine-stimulated nitric oxide release in saphenous veins, which suggests that aprotinin does not interfere with endothelial function. It is also highly unlikely that aprotinin is masking an attenuating effect on acetylcholine-induced relaxations by attenuating the U46619 preconstriction inasmuch as (1) there was no significant difference in the preconstriction between control and aprotinin-treated tissue and (2) as shown in Fig. 2 there was no difference in the degree of constriction with U46619 $(1 \mathrm{nmol} / \mathrm{L})$ between control and aprotinin-treated tissues. Finally, although acetylcholine is known to produce vasoconstriction of vascular smooth muscle at high concentrations, this was never seen in the concentration range used in our relaxation experiments. Whether acetylcholine relaxations would have been altered in ITAs was not examined in this study because of the limited availability of tissue. It may be argued that smaller diameter arteries are more prone to clinically relevant vasoconstriction than veins. However, ITAs are known to produce greater relaxations than veins. This, together with our present results in the saphenous vein, would argue against an attenuation of relaxations caused by aprotinin. Previous studies have shown that aprotinin does not inhibit release of prostacyclin or von Willebrand's factor from cultured human endothelial cells. ${ }^{17}$ This could have important clinical implications because nitric oxide and prostacyclin act synergistically in providing a mechanism to protect from spasm and inhibit platelet aggregation and smooth muscle cell proliferation.

A novel finding in the present study was that aprotinin attenuated the powerful vasoconstrictor action of U46619 in the saphenous vein. This effect appeared to be site specific because no attenuation of U46619 responses in the ITA were reported after aprotinin treatment. It seems unlikely that this effect was a result of some chemical interaction of aprotinin with U46619 because there was no effect on contractions in the artery. It also appears that the effect is specific to the $\mathrm{TXA}_{2}$ receptor pathway because no significant differences in responses to 5-HT or noradrenaline were found, although a nonspecific effect of aprotinin cannot be ruled out if a greater number of experiments were to be performed. The ability of aprotinin to influence $\mathrm{TXA}_{2}$ is further supported by the finding that TXA $\mathrm{T}_{2}$ levels after cardiopulmonary bypass are reduced in patients given aprotinin treatment. ${ }^{1-3}$ The mechanism or mechanisms responsible for this effect are not known, but could help in clarifying the mechanism of the ability of aprotinin to arrest bleeding and the overall safety of its therapy. After vascular injury the arrest of bleeding is controlled by (1) local vasoconstriction, (2) formation of a platelet plug, and (3) clot formation. It is also possible that by reducing the local powerful $\mathrm{TXA}_{2}$ contractions, aprotinin could aid platelet adhesion by reducing the forces generated at the site of inflammation by increasing vasomotor stability and thus contribute to stabilizing the platelet plug.

It has been suggested that aprotinin may cause premature saphenous vein graft occlusion. ${ }^{9,10}$ The evidence of vein graft thrombosis raises the question of a hypercoagulable state that may adversely influence patient outcome. Our data suggest that the preservation of endothelial cell nitric oxide function together with the reduced vasoconstrictor action of the saphenous vein with U46619 in the presence of aprotinin could reduce the chances of vein graft thrombosis by favoring antithrombotic aspects of vessel wall function.

The major limitation of this study is that the effects of aprotinin were examined in a blood-free system. Because aprotinin has several interactions with blood components that could influence its overall effect on blood vessel physiologic processes, our results with use of an organ bath system, which used physiologic Tyrode's solution to bathe the vessels, would need to be confirmed in a bloodperfused vessel to further confirm the ability of aprotinin to affect vascular reactivity.

In conclusion, aprotinin preserved endothelial function and counteracted the potent contractions of U46619 in the saphenous vein. These findings could help in the understanding of the mechanisms of action of aprotinin and have important clinical implications with regard to the possible effect of the drug in bypass graft function.

\section{REFERENCES}

1. Van Oeveren W, Jansen NJG, Bidstrup BP, et al. Effects of aprotinin on hemostatic mechanisms during cardiopulmonary bypass. Ann Thorac Surg 1987;44:640-5.

2. Bidstrup BP, Royston D, Sapsford RN, Taylor KM. Reduction in blood loss and blood use after cardiopulmonary bypass with high dose aprotinin. J Thorac Cardiovasc Surg 1989;97:364-72.

3. Blauhut B, Gross C, Necek S, Doran JE, Spath P, Lundsgaard-Hartsen P. Effects of high-dose aprotinin on blood loss, platelet function, fibrinolysis, complement, and renal function after cardiopulmonary bypass. J Thorac Cardiovasc Surg 1991;101:958-67. 
4. Hunt BJ, Yacoub M. Aprotinin and cardiac surgery [Editorial]. BMJ 1991;303:660-1.

5. Kallis P, Tooze JA, Talbot S, Cowarts D, Bevan DH, Treasure T. Aprotinin inhibits fibrinolysis, improves platelet adhesion and reduces blood loss. Eur J Cardiothorac Surg 1994;8:315-23.

6. Tabuchi N, De Haan J, Boonstra PW, Gallandat Huet RCG, Van Oeveren W. Aprotinin effect on platelet and clotting during cardiopulmonary bypass. Eur J Cardiothorac Surg 1994;8:87-90.

7. Van Oeveren W, Eijsman L, Roozendaal KJ, Wildevuur CRH. Platelet preservation by aprotinin during cardiopulmonary bypass. Lancet 1988;1586:644.

8. Nievelstein PFEM, de Groot PG. Interaction of blood platelets with the vessel wall. Hacmostasis 1988;37:89-91.

9. Cosgrove DM III, Heric B, Lytle BW, et al. Aprotinin therapy for reoperative myocardial revascularization: placebo-controlled study. Ann Thorac Surg 1992;54:1031-8.

10. Sundt T III, Kouchoukos NT, Saffitz JE, Murphy SF, Wareing TH, Stahl JS. Renal dysfunction and intravascular coagulation with aprotinin and hypothermic circulatory arrest. Ann Thorac Surg 1993;55:659-61.

11. Royston D, Bidstrup BP, Taylor KM, Sapsford RN. Effect of aprotinin on the need for blood transfusion after repeat open heart surgery. Lancet 1987;(ii):1289-91.

12. Fritz $\mathrm{H}$, Wunder $\mathrm{G}$. Biochemistry and applications of aprotinin, the kallikrein inhibitor. Drug Res 1983;33:474-94.

13. Tanaka K, Takao M, Yada I, Yuasa H, Kusagawa M, Deguchi K. Alterations in coagulation and fibrinolysis associated with cardiopulmonary bypass during open-heart surgery. J Cardiothorac Vasc Anesth 1989;3:181-8.

14. Van Oeversen W, Harder MP, Roozendaal KJ, Eijsman L, Wildervuur CRH. Aprotinin protects platelets against the initial effects of cardiopulmonary bypass. J Thorac Cardiovase Surg 1990;99:788-99.

15. Radomski MW, Palmer RMJ, Moncada S. The role of nitric oxide and cGMP in platelet adhesion to vascular endothelium. Biochem Biophys Res Commun 1987;148:1482-9.

16. Sneddon JM, Vane JR. Endothelium-derived relaxing factor reduces platelet adhesion to bovine endothelial cells. Proc Natl Acad Sci 1988;85:2800-4.

17. Royston BD, Royston D, Coade SB, Morgan DML, Pearson JD. Aprotinin does not inhibit the release of $\mathrm{PGI}_{2}$ or $\mathrm{vWF}$ from cultured human endothelial cells. Thromb Haemost $1992 ; 67: 172-5$. 